\title{
Microduplication of 4p16.3 Due to an Unbalanced Translocation Resulting in a Mild Phenotype
}

\author{
Erin P. Carmany* and Erawati V. Bawle \\ Division of Genetic and Metabolic Disorders, Department of Pediatrics, Wayne State University and Children's Hospital of Michigan, \\ Detroit, Michigan
}

Received 29 July 2010; Accepted 23 December 2010

With the widespread clinical use of comparative genomic hybridization chromosomal microarray technology, several previously unidentified clinically significant submicroscopic chromosome abnormalities have been discovered. Specifically, there have been reports of clinically significant microduplications found in regions of known microdeletion syndromes. In general, these microduplications have distinct features from those described in the corresponding microdeletion syndromes. We present a $5 \frac{1}{2} / 2$-year-old patient with normal growth, borderline normal IQ, borderline hypertelorism, and speech and language delay who was found to have a submicroscopic $2.3 \mathrm{Mb}$ terminal duplication involving the two proposed WolfHirschhorn syndrome (WHS) critical regions at chromosome 4p16.3. This duplication was the result of a maternally inherited reciprocal translocation involving the breakpoints $4 \mathrm{p} 16.3$ and 17q25.3. Our patient's features are distinct from those described in WHS and are not as severe as those described in partial trisomy $4 \mathrm{p}$. There are two other patients in the medical literature with 4p16.3 microduplications of similar size also involving the WHS critical regions. Our patient shows clinical overlap with these two patients, although overall her features are milder than what has been previously described. Our patient's features expand the knowledge of the clinical phenotype of a $4 \mathrm{p} 16.3$ microduplication and highlight the need for further information about it.

(C) 2011 Wiley-Liss, Inc.

Key words: chromosomes; human; pair 4; Wolf-Hirschhorn syndrome; chromosome duplication; microarray analysis; translocation; genetic

\section{INTRODUCTION}

With the advent of comparative genomic hybridization (CGH) chromosomal microarray technology, several clinically significant submicroscopic duplications in regions known to cause microdeletion syndromes have been identified. The features of these microduplication syndromes are clinically distinct from the microdeletion syndromes that share the same regions. Some of these include duplication of 22q11.2, the region involved in Velocardiofacial syndrome [Portnoi, 2009], duplication of 7q11.23, the region involved in Williams syndrome [Van der Aa et al., 2009], and
How to Cite this Article:

Carmany EP, Bawle EV. 2011.

Microduplication of $4 \mathrm{p} 16.3$ due to an

unbalanced translocation resulting in a mild phenotype.

Am J Med Genet Part A 155:819-824.

duplication of $17 \mathrm{p} 11.2$ (Potocki-Lupski syndrome), the region involved in Smith-Magenis syndrome [Potocki et al., 2007].

We present a $5^{1} / 2$-year-old female patient with a submicroscopic $2.3 \mathrm{Mb}$ terminal duplication of $4 \mathrm{p} 16.3$. This duplication involves the two proposed critical regions for Wolf-Hirschhorn syndrome (WHS), which is a well-characterized microdeletion syndrome caused by a deletion of $4 \mathrm{p} 16.3$. The first critical region, called WHSCR 1 , is a $165 \mathrm{~kb}$ area approximately $2 \mathrm{Mb}$ from the telomere of $4 \mathrm{p}$ and includes the genes WHSC1 and WHSC2 [Wright et al., 1997, 1999; Stec et al., 1998]. The second critical region, called WHSCR2, includes WHSC1 and LETM1 and is contiguous and telomeric to WHSCR1. It is estimated to be $300-600 \mathrm{~kb}$ in size positioned between 1.9 and $1.6-1.3 \mathrm{Mb}$ from the telomere [Zollino et al., 2003].

Our patient's clinical features are distinct from those described in WHS and are not as severe as those found in individuals with cytogenetically detectable partial trisomy 4p [Gonzalez et al., 1977; Patel et al., 1995; Battaglia et al., 2002]. This case provides further information regarding the clinical significance and variability of a microduplication of 4 p16.3.

\section{CLINICAL REPORT}

Our patient was initially referred at age 4 years, 4 months for evaluation of a mild intention tremor, speech delay, and dysmorphic facial features. She was born to a 26 -year-old, primagravida

\section{${ }^{*}$ Correspondence to:}

Erin P. Carmany, M.S., CGC, Division of Genetic and Metabolic Disorders, Children's Hospital of Michigan, 3901 Beaubien Blvd., Detroit, MI 48201.

E-mail: ecarmany@dmc.org

Published online 15 March 2011 in Wiley Online Library

(wileyonlinelibrary.com).

DOI 10.1002/ajmg.a.33916 
female. The pregnancy was uncomplicated and there were no teratogenic exposures. She was delivered at 40 weeks gestation by cesarean for breech presentation. Birth weight was $2.89 \mathrm{~kg}$ (10th centile); length was $47 \mathrm{~cm}$ (10th centile). Head circumference and APGARS were unknown. She was diagnosed with bilateral hip dysplasia and required a harness for 5 weeks. A cardiologist diagnosed her as having an innocent heart murmur. She also had a normal ophthalmology examination.

There were no concerns for her early developmental milestones. She reportedly sat at 5 months, took her first steps at 12 months, and spoke her first words at 9 months. There were concerns regarding her speech pronunciation at 18 months of age. She could speak two word phrases at approximately $2 \frac{1}{2}-3$ years of age. Her developmental assessment at $3 \frac{1}{2}$ years of age showed delays in her communication skills as well as mild delays in her gross and fine motor skills. She had been evaluated by a neurologist for a mild intention tremor. Developmental delay was noted but no specific cause for the tremor was identified. Our physical examination at age 4 years, 4 months showed: weight $15.8 \mathrm{~kg}$ (50th centile); height $99.0 \mathrm{~cm}$ (25th centile), and head circumference $49.5 \mathrm{~cm}$ (just $<50 \mathrm{th}$ centile). She had borderline hypertelorism with an intercanthal distance of $3.25 \mathrm{~cm}$ (90th centile). There were no other dysmorphic features (Fig. 1). Neurologic examination was negative; we did

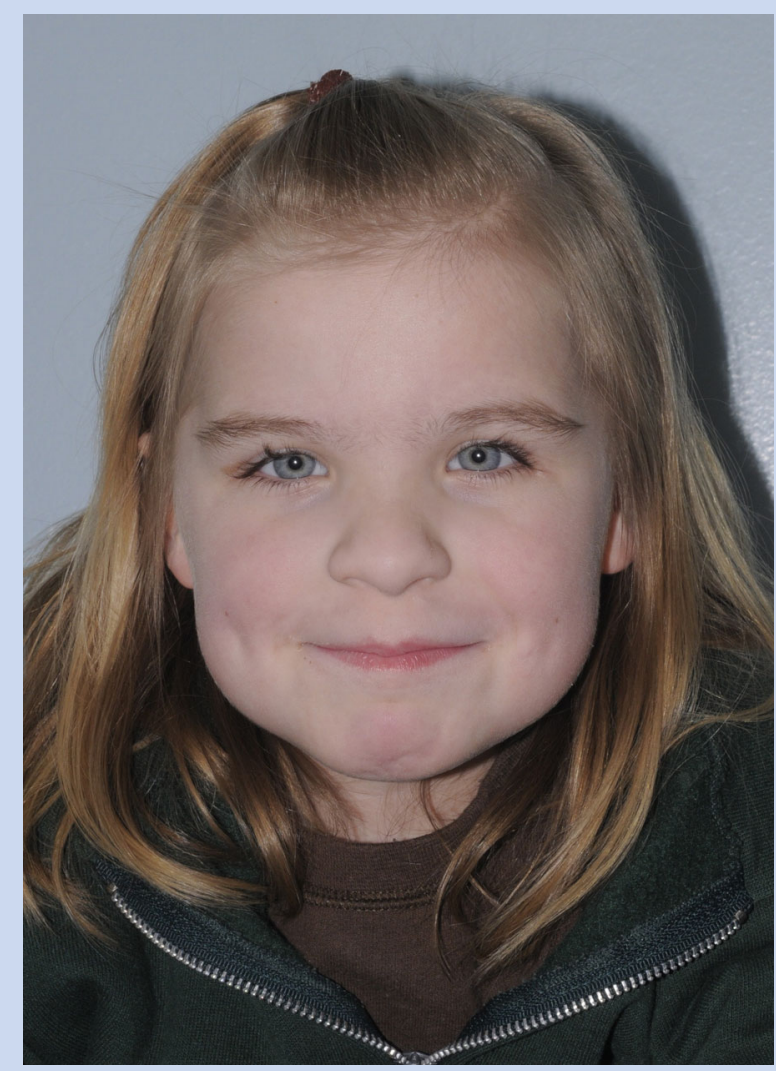

FIG. 1. Our patient at 6-year old. She has borderline hypertelorism but otherwise has no notable dysmorphic features. [Color figure can be viewed in the online issue, which is available at wileyonlinelibrary.com.] not notice the intention tremor. Karyotype was normal female 46,XX.

The patient was seen for a follow-up visit at $5^{1} / 2$ years of age. In addition to the above, she had developed pubic hair at 5 years of age. An endocrine evaluation was normal. Her bone age was found to be between 7 years, 10 months and 8 years, 10 months which is advanced in comparison to her chronologic age of 5 years, 7 months at the time of the evaluation. She also had a reported history of polyuria/polydipsia and night-time intermittent urinary incontinence. Her serum electrolytes were normal. She had WPPSI-III performed at $5^{1} / 2$ years of age which showed a full scale IQ of 80 ; verbal IQ of 80 ; performance IQ of 88 . She was found to have poor adaptive behavior, poor communication, and moderate-tosevere delays in receptive and expressive speech. On physical examination, weight was $20.2 \mathrm{~kg}$ (50th-75th centile); height was $105 \mathrm{~cm}$ (10th centile), and head circumference was $50.5 \mathrm{~cm}$ (50th centile). Her facial features were unchanged. Her breast development was at Tanner stage I. There was slight dark pubic hair over the labia majora. Her neurologic examination showed no abnormality.

The patient's younger sister presented to us at the same time as our patient at 5 months of age for an initial evaluation for failure to thrive. The sister's evaluation was unremarkable aside from the failure to thrive. The sister presented again at 21 months, at the same time as our patient, with failure to thrive and the additional findings of developmental delay and a new onset of seizures. At this follow-up visit, we drew the sister's blood for chromosomal microarray analysis.

Family history was remarkable for a 40 -year-old maternal great aunt who reportedly has short stature, intellectual disability, and seizures of unknown etiology.

\section{METHODOLOGY AND RESULTS Oligonucleotide aCGH}

Oligonucleotide-based microarray analysis was performed using a $105 \mathrm{~K}$-feature whole-genome microarray (SignatureChip Oligo Solution $^{\circledR}$, designed by Signature Genomic Laboratories (Spokane, WA) and Agilent Technologies (Santa Clara, CA) and made by Agilent Technologies) as previously described [Ballif et al., 2008]. Our patient's sister was found to have the following result: arr 4p16.3(35,881-2,297,002)x1,17q25.3(78,323,289-78,637,842)x3. This resulted in a terminal deletion at 4 p16.3 which was approximately $2.3 \mathrm{Mb}$ in size and a terminal duplication at $17 \mathrm{q} 25.3$ which was approximately $314.6 \mathrm{~kb}$ in size. The $4 \mathrm{p} 16.3$ deletion involves both WHSCR1 and WHSCR2 (Figs. 2 and 3).

\section{Fluorescence In Situ Hybridization (FISH) Analysis}

Metaphase FISH analysis was performed using BAC clones RP11478C6 and RP11-46H21 to visualize the abnormalities as previously described [Traylor et al., 2009]. These results confirmed that the sister's abnormality was the result of an unbalanced translocation between 4 p16.3 and 17q25.3. This abnormality, together with the sister's clinical features, confirmed a diagnosis of WHS in her. 


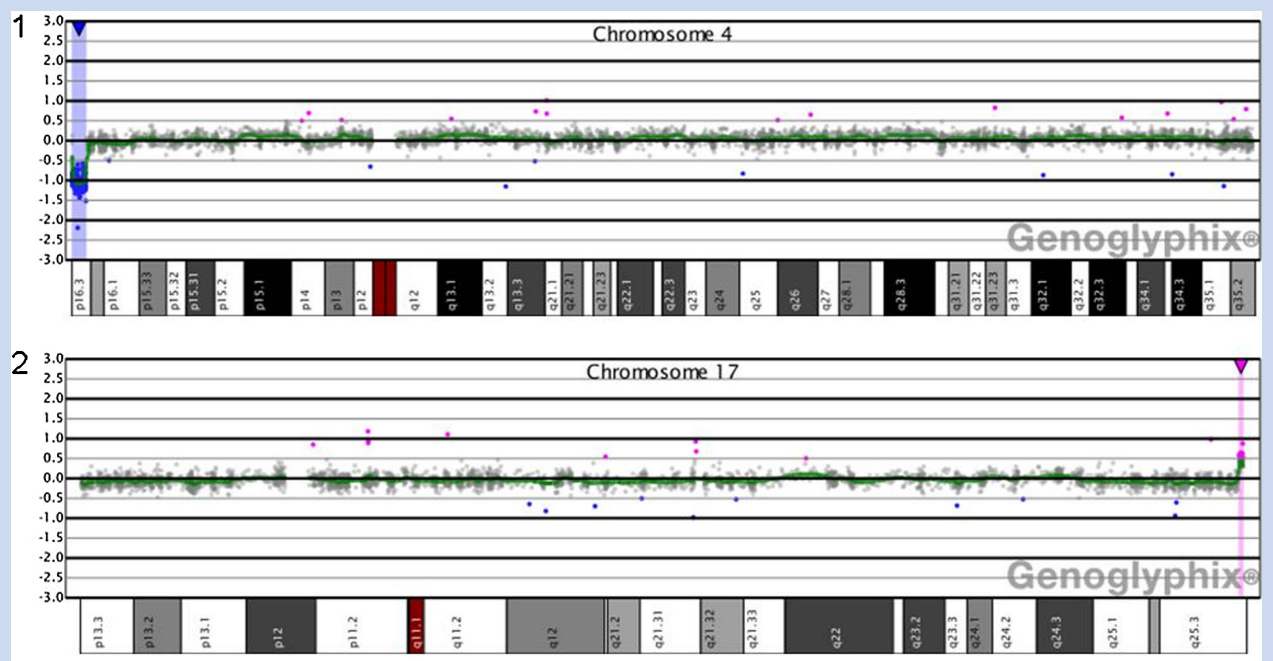

FIG. 2. Microarray characterization of the unbalanced translocation resulting in deletion of $4 \mathrm{p} 16.3$ and a duplication of $17 \mathrm{q} 25.3$ in the sister of our patient. [1] Microarray plot showing a single-copy loss of 149 oligonucleotide probes from the short arm of chromosome 4 at 4 p16.3 [chr4:35,881-2,297,002, hg 18 assembly], approximately $2.3 \mathrm{Mb}$ in size. Probes are ordered on the x-axis according to physical mapping positions, with the most distal p-arm probes to the left and the most distal q-arm probes to the right. (2) Microarray plot showing a single-copy gain of 37 oligonucleotide probes from the long arm of chromosome 17 at $17 q 25.3$ [chr17:78,323,289-78,637,842] approximately 315 kb in size. Probes are ordered as in 1. Results are visualized using Genoglyphix software [Signature Genomics]. [Color figure can be viewed in the online issue, which is available at wileyonlinelibrary.com.]

Following the sister's results, metaphase FISH analysis was performed on the mother and then subsequently on our patient. The mother's FISH results detected a balanced translocation between 4p16.3 and 17q25.3 (Fig. 4). Our patient was detected as having the reciprocal version of the unbalanced translocation, namely a terminal duplication at 4 p16.3 and a terminal deletion at $17 \mathrm{q} 25.3$ (Fig. 5). Thus far, no other family members have been tested for the presence of this translocation.

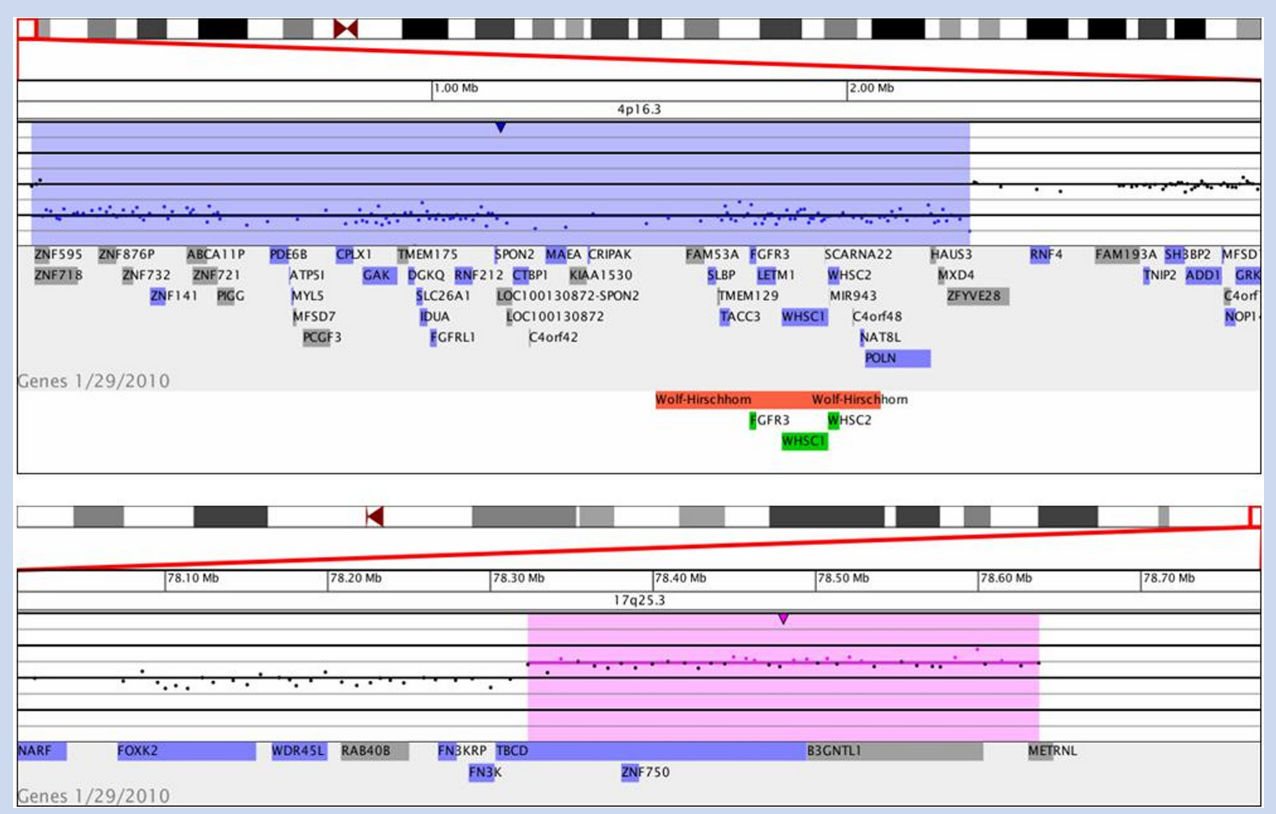

FIG. 3. Graphical representation of the regions involved in the translocation. Purple box: Chromosome 4p region. Pink box: Chromosome 17q region. Red and green boxes: Wolf-Hirschhorn critical region. Blue boxes: $0 \mathrm{MIM}$ genes. Gray boxes: 0 ther genes in region. [Color figure can be viewed in the online issue, which is available at wileyonlinelibrary.com.] 

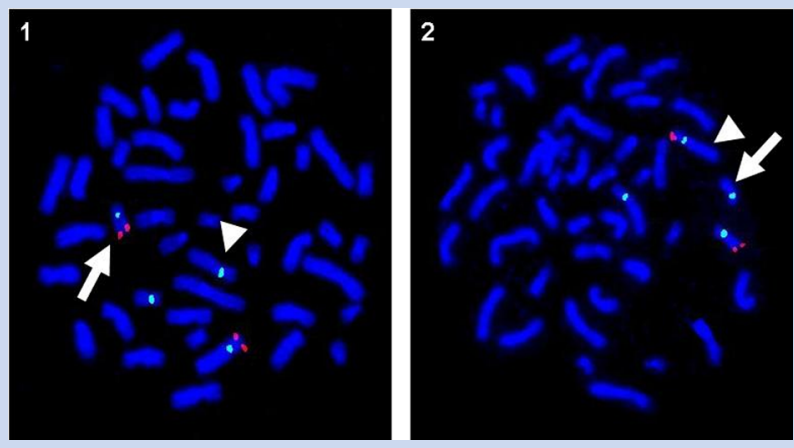

FIG. 4. FISH in the mother showing a reciprocal translocation between $4 p 16.3$ and 17q25.3. (1) FISH showing derivative 17 (long arrow) with presence of signal from BAC clone RP11-478C6 from the 4p16.3 region (labeled in red) and derivative 4 (short arrow] with absence of signal from clone RP11-478C6. (2) FISH showing derivative 4 (short arrow) with presence of signal from BAC clone RP11-46H21 from the 17q25.3 region (labeled in red) and derivative 17 (long arrow) with absence of signal from RP11-46H21. In both panels, chromosome 4 centromere probe D4Z1 and chromosome 17 centromere probe D17Z1 are labeled in green as controls. [Color figure can be viewed in the online issue, which is available at wileyonlinelibrary.com.]

\section{DISCUSSION}

We present a case of a submicroscopic duplication of $4 \mathrm{p} 16.3$ involving the WHS critical regions. This case is clinically distinct from both WHS and the trisomy $4 \mathrm{p}$ syndrome. The classic clinical features of WHS include prenatal and postnatal growth retardation,
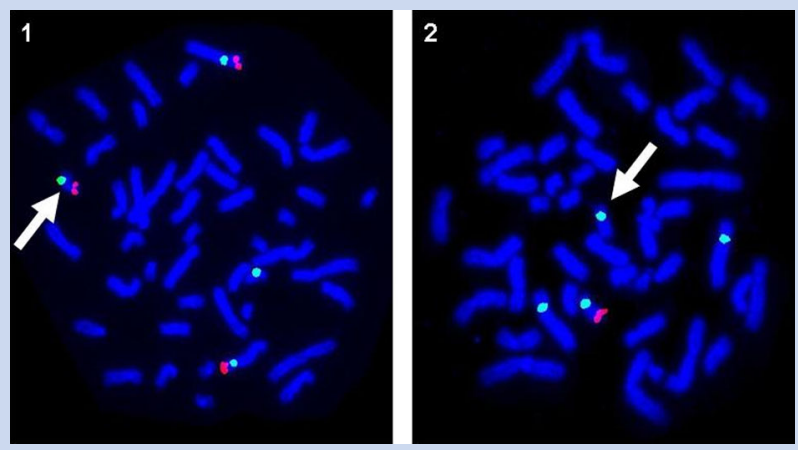

FIG. 5. FISH in patient showing a derivative chromosome 17 with a duplication of 4 p16.3 and a deletion of 17q25.3. (1) FISH showing derivative 17 [arrow] with presence of signal from BAC clone RP11-478C6 from the 4p16.3 region, labeled in red. (2) FISH showing derivative 17 (arrow) with absence of signal from BAC clone RP11-46H21 from the $17 q 25.3$ region, labeled in red. In both panels, chromosome 4 centromere probe D4Z1 and chromosome 17 centromere probe $\mathrm{D} 17 \mathrm{Z1}$ are labeled in green as controls. [Color figure can be viewed in the online issue, which is available at wileyonlinelibrary.com.] intellectual disability, seizures, and distinctive dysmorphic facial features described as a "Greek warrior helmet" facies [Battaglia et al., 2008]. Our patient does not have any of these classic features and there is very little clinical overlap of her features with WHS.

Trisomy $4 \mathrm{p}$ is a distinct clinical entity that has been described in more than 75 cases. In general, patients are trisomic for at least the distal $2 / 3$ of $4 \mathrm{p}$. Clinical features include growth retardation, psychomotor retardation, cardiac anomalies, and renal anomalies. The dysmorphic features include a prominent glabella, bulbous nose with a flat nasal bridge, retrognathia, abnormal ears, and rocker bottom feet [Gonzalez et al., 1977; Patel et al., 1995]. There have been several patients with trisomy $4 p$ described in the medical literature that have documented involvement of the WHS loci, however, almost all cases have been cytogenetically detectable duplications, and, therefore, larger than the duplication present in our case [Cotter et al., 2001; Tschernigg et al., 2002; GerardBlanluet et al., 2004; Takeno et al., 2004; Bartocci et al., 2008]. Our patient has none of the severe features described in these patients.

Thus far, there have been only two other cases in the medical literature with submicroscopic duplications of $4 p$ involving the WHS critical regions. Roselló et al. [2009] describe a 10-year-old boy who was found to have a $1.1 \mathrm{Mb}$ duplication involving the WHS critical regions. However, he also had a $1.3 \mathrm{Mb}$ distal deletion of 4p. It has been suggested that a deletion distal to the WHS critical regions may be responsible for seizures, developmental delay, and growth retardation seen in some patients with a "mild" WHS phenotype [South et al., 2008]. Therefore, his phenotype may not be solely explained by his duplication of $4 \mathrm{p} .16 .3$. However, there still is clinical overlap between our case and this patient including hypertelorism, normal height, and developmental delay most significant in speech (Table I).

More recently, Hannes et al. [2010] presented a 15-month-old child with a $560 \mathrm{~kb}$ interstitial duplication of $4 \mathrm{p} 16.3$ also involving the WHS critical regions. He additionally was found to have an inversion between $4 \mathrm{p} 16.3$ and $4 \mathrm{q} 22$. His clinical features are much more significant than our patient and the patient presented by Roselló et al. [2009] and include a hand malformation, hypotonia, glaucoma of the left eye, and development at a 5-month old level (Table I). Given the severity of his features, it is possible that his inversion may be affecting his phenotype in some way, possibly by a gene disruption of some kind.

Our patient, in addition to the terminal duplication of $4 \mathrm{p} 16.3$, has a $314.6 \mathrm{~kb}$ deletion of $17 \mathrm{q} 25.3$. Thus far, there have not been any cases in the medical literature with a deletion of $17 \mathrm{q} 25.3$ of this size causing a clinically significant phenotype. In fact, there has been some evidence to suggest that a deletion of $17 \mathrm{q} 25.3$ is a benign copy number variant [Balikova et al., 2007]. There are only four genes in the $17 \mathrm{q} 25.3$ region. Tubulin-specific chaperone D (TBCD) has been found to be expressed in brain tissue [Nagase et al., 1999]. Zinc finger protein 750 (ZNF750) has been found to be expressed in several tissues including human keratinocytes but not in the brain [Birnbaum et al., 2006]. Beta $3 \mathrm{~N}$-acetyleglucosaminyltransferase (B3GNTL1) was isolated from fetal brain cDNA but was found to be expressed most significantly in the adult pancreas [Zheng et al., 2004]. And finally, Meteorin (METRNL) is thought to be involved in neurogenesis and in angiogenesis at the glialvascular interface [Nishino et al., 2004; Park et al., 2008]. Despite the fact that 3 of 
TABLE I. A Comparison of Our Patient to Two Patients in the Literature

\section{Features}

4p16.3 duplication size

4p16.3 duplication location

Other chromosome anomalies

\section{Age}

Height

Weight

Speech delay

Full scale IQ

Developmental delay

Seizures

Hypertelorism/abnormal

palpebral fissures

Epicanthic folds

Low set/abnormal ears

Other abnormalities

\section{Our patient}

$2.3 \mathrm{Mb}$

35,881-2,297,002

$314.6 \mathrm{~kb}$ terminal

deletion of $17 q 25.3$

$5 \frac{1}{2}$ years

Normal

50th centile

Yes

80

Yes

No

Yes

No

No

Premature pubarche, advanced bone age, mild intention tremor, congenital hip dysplasia
Roselló et al. [2009]

1.1 $\mathrm{Mb}$

Approx. 1,300,000-2,400,000

1.3 $\mathrm{Mb}$ terminal

deletion of $4 \mathrm{p} 16.3$

$9 \frac{1}{2}$ years

Normal

$<11$ th centile

Yes

Not reported

Yes

Yes

Yes

Yes

Yes

Hyperactivity,

behavioral problems
Hannes et al. [2010] $560 \mathrm{~kb}$

1,458,385-1,907,425

inv (4) (p16.3q22)

15 months

Not reported

$<3$ rd centile

Yes

Not reported

Yes

Yes

Yes

Yes

Yes

Hypotonia, unilateral hand abnormality, unilateral glaucoma, high arched

palate, bilateral single transverse

crease, short neck these 4 genes are expressed in the brain, there is no information indicating if haploinsufficiency of any of these genes is sufficient to cause a clinically significant phenotype. However, we cannot rule out the possibility that the deletion at $17 \mathrm{q} 25.3$ could be contributing to our patient's phenotype.

Our patient's case illustrates several important concepts. She presents with a relatively mild phenotype when compared to other individuals with a duplication of $4 \mathrm{p} 16.3$. Her mild phenotype suggests that there may be wide variability of the features associated with this duplication. Additionally, our case helps provide prognostic information regarding microduplications in general. Our patient's phenotype is milder than what has been described in WHS even in those cases involving small deletions of 4 p16.3 $<3.5 \mathrm{Mb}$ [Zollino et al., 2008]. Therefore, our patient's case provides further evidence that, in general, microduplications are better tolerated than microdeletions of the same region. Additionally, our patient provides further evidence of the pathogenic nature of copy number changes in areas known to involve dosage-sensitive genes. It has been suggested that the same dosage-sensitive genes known to be pathogenic when haploinsufficient in microdeletion syndromes may cause different phenotypic consequences if they are over-expressed. Portnoi [2009] suggests that over-expression of TBX1 (a major gene associated with the Velocardiofacial/Digeorge syndrome phenotype) may be the cause of the 22q11.2 microduplication syndrome. Potocki et al. [2007] has proposed that the RAI1 gene (a gene thought to be causative in Smith-Magenis syndrome) may be responsible for the features of Potocki-Lupski syndrome when over-expressed. While our single case does not help us identify which of the genes in the WHS critical regions may be responsible for our patient's phenotype, it suggests that there may be genes in the region that are sensitive to overexpression.

In conclusion, our patient's case helps expand the understanding of the nature of pathogenic microduplications in general. Additionally, it provides evidence that a microduplication of 4 p16.3 involving the WHS critical regions causes a clinically relevant phenotype, likely with extreme variability. It also highlights the need for further research on pathogenic microduplications involving dosage-sensitive genes in general and more specifically on the emerging phenotype associated with a microduplication of 4 p16.3.

\section{ACKNOWLEDGMENTS}

We would like to thank Signature Genomics, Inc. for providing the figures and testing methodology and the family for their assistance with publishing this case.

\section{REFERENCES}

Balikova I, Menten B, de Ravel T, Le Caignec C, Thienpont B, Urbina M, Doco-Fenzy M, de Rademaeker M, Mortier G, Kooy F, van Den Ende J, Devriendt K, Fryns JP, Speleman F, Vermeesch JR. 2007. Subtelomeric imbalances in phenotypically normal individuals. Hum Mutat 28:958-967.

Ballif BC, Theisen A, McDonald-McGinn DM, Zackai EH, Hersh JH, Bejjani BA, Shaffer LG. 2008. Identification of a previously unrecognized microdeletion syndrome of 16q11.2q12.2. Clin Genet 74:469-475.

Bartocci A, Striano P, Mancardi MM, Fichera M, Castiglia L, Galesi O, Michelucci R, Elia M. 2008. Partial monosomy Xq(Xq23-qter) and trisomy $4 \mathrm{p}(4 \mathrm{p} 15.33$-pter $)$ in a woman with intractable focal epilepsy, 
borderline intellectual functioning, and dysmorphic features. Brain Dev 30:425-429.

Battaglia A, Brothmann AR, Carey JC. 2002. Recombinant 4 syndrome due to an unbalanced pericentric inversion of chromosome 4. Am J Med Genet 112:103-106.

Battaglia A, Filippi T, Carey J. 2008. Update on the clinical features and natural history of Wolf-Hirschhorn $(4 \mathrm{p}-)$ syndrome: Experience with 87 patients and recommendations for routine health supervision. Am J Med Genet Part C 148C:246-251.

Birnbaum RY, Zvulunov A, Hallel-Halevy D, Cagnano E, Finer G, Ofir R, Geiger D, Silberstein E, Feferman Y, Birk OS. 2006. Seborrhea-like dermatitis with psoriasiform elements caused by a mutation in ZNF750, encoding a putative $\mathrm{C} 2 \mathrm{H} 2$ zinc finger protein. Nature Genet 38:749-751.

Cotter PD, Kaffe S, Li L, Gershin IF, Hirschhorn K. 2001. Loss of subtelomeric sequence associated with a terminal inversion duplication of the short arm of chromosome 4. Am J Med Genet 102:76-80.

Gerard-Blanluet M, Romana S, Munier C, Le Lorc'h M, Kanafani S, Sinico M, Touboul C, Levaillant JM, Haddad B, Lopez N, Lelong F, Billette de Villemeur T, Verloes A, Borghi E. 2004. Classical West "syndrome" phenotype with a subtelomeric $4 p$ trisomy. Am J Med Genet Part A 130A: 299-302.

Gonzalez CH, Sommer A, Meisner LF, Elejalde BR, Opitz JM. 1977. The trisomy $4 \mathrm{p}$ syndrome: Case report and review. Am J Med Genet $1: 137-156$.

Hannes F, Drozniewska M, Vermeesch JR, Haus O. 2010. Duplication of the Wolf-Hirschhorn syndrome critical region causes neurodevelopmental delay. Eur J Med Genet 53:136-140.

Nagase T, Ishikawa K, Suyama M, Kikuno R, Hirosawa M, Miyajima N, Tanaka A, Kotani H, Nomura N, Ohara O. 1999. Prediction of the coding sequences of unidentified human genes. XIII. The complete sequences of 100 new cDNA clones from brain which code for large proteins in vitro. DNA Res 6:63-70.

Nishino J, Yamashita K, Hashiguchi H, Fujii H, Shimazaki T, Hamada H. 2004. Meteorin: A secreted protein that regulates glial cell differentiation and promotes axonal extension. EMBO 23:1998-2008.

Park JA, Lee HS, Ko KJ, Park SY, Kim JH, Choe GY, Kweon HS, Song HS, Ahn JC, Yu YS, Kim KW. 2008. Meteorin regulates angiogenesis at the gliovascular interface. Glia 56:247-258.

Patel S, Dagnew H, Parekh A, Koenig E, Conte R, Macera M, Verma R. 1995. Clinical manifestations of trisomy $4 \mathrm{p}$ syndrome. Eur J Pediatr 154: 425-431.

Portnoi MF. 2009. Microduplication 22q11.2: A new chromosomal syndrome. Eur J Med Genet 52:88-93.

Potocki L, Bi W, Treadwell-Deering D, Carvalho CMB, Eifert A, Friedman EM, Glaze D, Krull K, Lee JA, Lewis RA, Mendoza-Londono R, RobbinsFurman P, Shaw C, Shi X, Weissenberger G, Withers M, Yatsenko SA, Zackai EH, Stankiewicz P, Lupski JR. 2007. Characterization of Potocki-Lupski syndrome $(\operatorname{dup}(17)(\mathrm{p} 11.2 \mathrm{p} 11.2))$ and delineation of a dosage-sensitive critical interval that can convey an autism phenotype. Am J Hum Genet 80:633-649.

Roselló M, Monfort S, Orellana C, Ferrer-Bolufer I, Quiroga R, Oltra S, Martínez F. 2009. Submicroscopic duplication of the Wolf-Hirschhorn critical region with a $4 \mathrm{p}$ terminal deletion. Cytogenet Genome Res 125: 103-108.

South ST, Hannes F, Fisch GS, Vermeesch JR, Zollino M. 2008. Pathogenic significance of deletions distal to the currently described Wolf-Hirschhorn syndrome critical regions on 4p16.3. Am J Med Genet Part C 148C:270-274.

Stec I, Wright TJ, van Ommen GJ, de Boer PA, van Haeringen A, Moorman AF, Altherr MR, den Dunnen JT. 1998. WHSC1, a 90kb SET domaincontaining gene, expressed in early development and homologous to a Drosophila dysmorphy gene maps in the Wolf-Hirschhorn syndrome critical region and is fused to IgH in $\mathrm{t}(4 ; 14)$ multiple myeloma. Hum Mol Genet 7:1071-1082.

Takeno SS, Corbani M, Andrade JAD, Smith MAC, Brunoni D, Melaragno MI. 2004. Duplication 4p and deletion 4p (Wolf-Hirschhorn syndrome) due to complementary gametes from a 3:1 segregation of a maternal balanced t $(4 ; 13)(\mathrm{p} 16 ; \mathrm{q} 11)$ translocation. Am J Med Genet Part A 129A: $180-183$.

Traylor RN, Fan Z, Hudson B, Rosenfeld JA, Shaffer LG, Torchia BS, Ballif BC. 2009. Microdeletion of 6q16.1 encompassing EPHA7 in a child with mild neurological abnormalities and dysmorphic features: Case report. Mol Cytogenet 2:17.

Tschernigg M, Petek E, Wagner K, Kroisel PM. 2002. Mild phenotype due to inverse duplication $4 \mathrm{p} 16.3-\mathrm{p} 15.3$ including the Wolf-Hirschhorn critical region. Genet Couns 13:29-33.

Van der Aa N, Rooms L, Vandeweyer G, Van den Ende J, Reyniers E, Fichera M, Romano C, Delle Chiaie B, Mortier G, Menten B, Destrée A, Maystadt I, Mannik K, Kurg A, Reimand T, McMullan D, Oley C, Brueton L, Bongers EMHF, Van Bon BWM, Pfund R, Jacquemont S, Ferrarini A, Martinet D, Schrander-Stumpel C, Stegmann APA, Frints SGM, De Vries BBA, Ceulemans B, Kooy RF. 2009. Fourteen new cases contribute to the characterization of the 7q11.23 microduplication syndrome. Eur J Med Genet 52:94-100.

Wright TJ, Ricke DO, Denison K, Abmayr S, Cotter PD, Hirschhorn K, Keinänen M, McDonald-McGinn D, Somer M, Spinner N, Yang-Feng T, Zackai E, Altherr MR. 1997. A transcript map of the newly defined $165 \mathrm{~kb}$ Wolf-Hirschhorn syndrome critical region. Hum Mol Genet 6:317-324.

Wright TJ, Costa JL, Naranjo C, Francis-West P, Altherr MR. 1999. Comparative analysis of a novel gene from the Wolf-Hirschhorn/PittRogers-Danks syndrome critical region. Genomics 59:203-212.

Zheng H, Lia Y, Ji C, Li J, Zhang J, Yin G, Xu J, Ye X, Wu M, Zou X, Gu S, Xie Y, Mao Y. 2004. Characterization of a cDNA encoding a protein with limited similarity to $\beta 1,3-N$-acetylglucosaminyltransferase. Mol Biol Rep 31:171-175.

Zollino M, Lecce R, Fischetto R, Murdolo M, Faravelli F, Selicorni A, Butte C, Memo L, Capovilla G, Neri G. 2003. Mapping the Wolf-Hirschhorn syndrome phenotype outside the currently accepted WHS critical region and defining a new critical region, WHSCR-2. Am J Hum Genet 72: 590-597.

Zollino M, Murdolo M, Marangi G, Pecile V, Galasso C, Mazzanti L, Neri G. 2008. On the nosology and pathogenesis of Wolf-Hirschhorn syndrome: Genotype-phenotype correlation analysis of 80 patients and literature review. Am J Med Genet Part C 148C:257-269. 